\title{
Gender-oriented Use of Vocabulary Strategies: A Comparative Study
}

\author{
Kamal Heidari Soureshjani \\ Islamic Azad University, Shahrekord Branch, Shahrekord, Iran \\ Email: k_tefl_h@yahoo.com
}

\begin{abstract}
In the recent decades there has been an increasing interest in vocabulary learning strategies given that they are found to facilitate second or foreign language vocabulary learning. Many people from different angles have focused on this aspect of language and done various studies regarding it. In the current paper, these strategies are studied and at last, by doing a survey and running a T-test, the study tried to examine if there is any difference in the Iranian male and female use of these strategies or not. Besides, it determined the most frequently-used and also the least frequently-used vocabulary learning strategies which language learners employ to learn new vocabulary items are ascertained. The study observed a significant difference in the male and female language learners' use of the strategies. It became also apparent that "connecting a word to its synonyms and antonyms" and "using physical actions" were the strategies which language learners most often use to find the meaning of new vocabulary items and "imaging word form" and "imaging word meaning" were the least frequently-used vocabulary learning strategies. Consideration of these strategies can be helpful in selecting the most effective strategies for vocabulary learning and as a result, reaching a higher degree of proficiency in this area of language.
\end{abstract}

Index Terms — vocabulary learning strategies, gender differences

\section{INTRODUCTION}

It is a truism and has also been repeatedly mentioned by different researchers that assessing vocabulary is necessary. They support this claim by arguing that words are the basic building blocks of language and it is the units of meaning from which larger structures such as sentences, paragraphs and whole texts are formed (Read, 2000; Schmitt, 2000). Considering the crucial role of vocabulary learning in second or foreign language learning contexts, one can makes aware of the importance of vocabulary teaching as well. In the past, vocabulary teaching and learning were often given little priority in second language programs, but recently there has been a renewed interest in the nature of vocabulary and its role in learning and teaching (Richards \& Renandya, 2002). Furthermore, some studies have shown lexical problems of language learners indicating that lexical problems frequently interfere with communication. In fact, communication breaks down when people do not use the right words (Allen, 1983). Therefore, there is an increased interest in vocabulary as a component of every language.

Over the past few decades, researchers and language teachers noticed that some learners seem to be successful in second or foreign language learning regardless of teaching methods and techniques. Therefore, a considerable number of researchers have shifted their focus from teaching methods or techniques to language learning strategy use. "Strategy", from the ancient Greek term strategia, refers to generalship or the art of war. In a more specific sense, strategy entails the optimal management of troops, ships or aircraft in a planned campaign. "Tactics" is different but related to strategies, which are tools to achieve the success of strategies. Moreover, the two expressions share some basic concepts: planning, competition, conscious manipulation and movement toward a goal. In nonmilitary settings, the concept of strategy has been applied to the non-adversarial situations, where it has come to mean a plan, step or an action is taken for achieving a specific objective (Oxford, 1990). Oxford (1990) stated that strategies are particularly important for language learning "because they are tools for active, self-directed involvement, which is essential for developing communicative competence" (p. 1). Because of its significance, learning strategies have been extensively employed in the educational field. In defining the language learning strategy, "different researchers use different terms and different concepts" (Oxford \& Crookall, 1989, p.414); therefore, a great number of researchers have formulated their own definitions which will be discussed in the followings.

Language learning strategies are also referred to as specific actions or techniques that learners use to assist their progress in developing second or foreign language skills (Oxford, 1990). Language learning strategies are believed to play a vital role in learning a second language, as they may assist learners in mastering the forms and functions required for reception and production in the second language and thus affect achievement (Bialystok, 1979). Many researchers have suggested that the conscious use of language learning strategies makes good language learners (Naiman, Frohlich \& Todesco, 1975; Wenden, 1985). Researchers believe that strategies of successful language learners can provide a basis for aiding language learners (Rubin, 1975; Reiss, 1983). Therefore, if language teachers know more about 
effective strategies that successful learners use, they may be able to teach these effective strategies to less proficient learners to enhance these learners' language skills.

\section{BACKGROUND TO THE STUDY}

One area of language which has been focused on sufficiently in language learning and teaching is vocabulary. The significance of this area of language is so much that some believed, in the past, that if somebody masters the vocabulary aspect of a language, he/she has undergone over the half of the way of language learning process. I don't agree on this claim completely. Because nowadays it is a truism that language has many aspects to be learned in order to be able to say that somebody has mastered the language. Despite all these statements, accepting this fact that vocabulary is among the most important aspects of language is inevitable. Regarding vocabulary aspect of language it should be reminded that this aspect of language has its own sub-sections like word frequency, vocabulary learning strategies and so on and so forth. The latter subsection which was mentioned above, that is, vocabulary learning strategies is the purpose of the present study. By vocabulary learning strategies it means the techniques, strategies and the approaches which language learners consciously employ to facilitate the learning of new vocabulary items. There are various types of these strategies used by different learners. Learners usually use one or more strategies for special reasons. For example, some learners use the "connecting new words to their experience" strategy because they have a high working memory. Or some others may use the "dictionary use" strategy because of their low working memory.

Regarding this topic, that is, vocabulary learning strategies, there have been done various researches and as a result, many findings have been obtained. These different studies have focused on this topic from different angles. These studies, whether practical or theoretical ones, have their own weaknesses and strengths. Among these different studies, the following ones are mentioned; because they are more related to the purpose which is to be achieved in the present study. According to researchers, vocabulary learning strategies facilitate acquisition of new lexis in the second or foreign languages as they aid in discovering the meaning of a new word and in consolidating a word once it has been encountered (Cohen, 1996; Nation, 2001; Schmitt, 1997). This finding is one of the findings which are usually obtained from most related studies.

Of course, many attempts have been made to develop taxonomy of vocabulary strategies mostly as part of a piece of research into learners' strategy use. Among these attempts, Schmitt's (1997) taxonomy can be mentioned as an example, which organized around Oxford's (1990) language learning strategies. This study reflected the different Processes necessary for working out a new word's meaning and usage, and for consolidating it in memory for future use. This list contained fifty eight strategies which were classified into five groupings, i.e., determination, social, memory, cognitive and meta cognitive strategies.

Some other researches regarding these strategies, found differences among learners in terms of strategy use for vocabulary. Successful vocabulary learners were found to be active strategy users who are aware of their learning process, where as poor learners are less active in using vocabulary learning strategies and they are not conscious of how they learn new items. (Ahmed, 1989; Sanaoui, 1995). Or in another research done by GU (2005), successful learners select intentionally, monitor consciously and evaluate carefully their strategy use for the fulfillment of their aim. Unsuccessful ones, on the other hand, use learning strategies and behaviors similar to their peers without being conscious and also without any aim (Gu, 1994; Gu, 2005). Regarding these findings, we can refer to this claim that learners need to be able to consciously apply a strategy to a cognitive process to strengthen the link between the strategy and the achievement of vocabulary learning (Macaro, 2005). Likewise, Cohen (1990) indicated that many learners don't develop sufficient mastery of strategy repertoire that will allow them to make progress in language learning on their own. Another point which can be understood from these claims is that, learners need to be given explicit instruction to become more aware of and proficient with the broad range of strategies that can be used through learning process (Cohen, Weaver, \& Li, 1998; Oxford, 1993, 1996; Wenden, 1991).

According to Schmitt $(1997,2000)$, in deciding which one of vocabulary learning strategies should be recommended to second language learners, we need to consider specific learning context as the effectiveness with which learning strategy can be both taught and used depends on a number of variables, i.e., the students' proficiency level, their motivation and the purpose of learning.

Other research looked at this topic from other angles. For example, waring (1997) focused on vocabulary learning in semantic sets and showed that presenting new vocabulary items in semantic sets facilitate learning (Waring, 1997; Folse, 2004). In fact, researches done on this topic showed that when similar words were introduced at the same time, it had an interfering effect on learning and that especially synonyms were learned very poorly by the learners (McGeoch and McDonald, 1931). This finding is related to the "interference theory "(Anderson, 1976; Reed, 2004).

All in all, the present study tries to consider the use of vocabulary learning strategies from a new window. That is, it examines first, if there is any significant difference between males and females in their use of the strategies. And second, what are the most and the least frequently-used strategies adopted by them. No need to say that conducting studies like the current one contribute significantly in gaining much more effective knowledge on better learning, teaching, and use of the strategies.

\section{METHODOLOGY}




\section{A. Participants}

Altogether 110 language learners, 50 male and 60 female, were randomly selected to take part in the study. They aged from 17 to 23 and all were taking high intermediate courses in two of language institutes in Shahrekord, Iran. The sampling procedure employed by the author was convenient approach meaning that he picked out the learners who were available to him. Finally, the main reason for deciding to do the study on the high-intermediate language learners was that in this level of proficiency the practice on vocabulary is much more than what is in elementary and lowintermediate levels.

\section{B. Materials}

In order to find out about the vocabulary learning strategies used by the participants, a frequently used vocabulary learning strategies adapted from Schmitt (2000) was used. This questionnaire was devised in three parts. In the first part different characteristics of participants were included and the participants were required to fill in the choice which is suitable for them. The second part contained about sixteen different kinds of vocabulary learning strategies and the participants were to select maximally three of them which they use most often while learning new vocabulary items. In the third and the final part of the card a space was provided for the participants so that, if participants used a strategy which was not mentioned in the card they could write it down in the provided part and also elaborated on it. The sample of this card is available at the end of the paper in the section of appendix.

\section{Data Analysis}

Before everything, the author gave a short speech regarding the topic of vocabulary learning strategies and their different types. He also talked about their application in the process of learning new vocabulary items. Then, some talk was made regarding the purpose of the paper and also about the way they should take part in the study as the participants. Having ensured that they got completely aware of their task, the questionnaire was distributed among them and they were required to fill them in and hand in the cards to the author within half an hour.

Having gathered the required data, in order to analyze them, SPSS version 16 in general and an independent t-test in particular was run to see if there is any significant difference among the male and females with regard to their use of vocabulary strategies. The author also made a frequency of the strategies named by them so that it became possible to determine the most and also the least frequency-used strategies.

\section{RESULTS AND DISCUSSION}

Having analyzed the data, now the main results of the study are presented in this section of the paper. Table 1 presents the preliminary descriptive information of the participants' responses. As it is evident from the table the mean of the responses (16.23) is to a large extent larger than the reported SD (10.67) meaning that there is some degree of consistency among the participants' use of vocabulary learning strategies. To gain more exact results and in order to see whether there is a significant difference between the male and female learners in terms of their use of vocabulary strategies, Table 2 can be a great help.

TABLE 1.

DESCRIPTIVE STATISTICS OF THE PARTICIPANTS' PERFORMANCE

\begin{tabular}{|l|l|l|l|l|}
\hline No & Min & Max & Mean & SD \\
\hline 110 & 1 & 4 & 16.23 & 10.67 \\
\hline
\end{tabular}

Table 2 reveals that there is a significant difference between the male and female learners in using the vocabulary learning strategies $(\mathrm{P} .=.01<.05)$.

TABLE 2.

INDEPENDENT T-TEST OF GENDER-ORIENTED STRATEGIY USE

\begin{tabular}{|l|l|l|l|l|l|l|}
\hline Variable & No & Mean & SD & S.E. of mean & DF & 2-tail sig. \\
\hline Gender*Voc.strategy & 110 & 26.23 & 10.67 & 3.570 & 33 & 0.01 \\
\hline
\end{tabular}

Then in order to pinpoint the most and the least frequently-used strategies adopted by language learners, the frequency of the strategies were taken into account. The following results were gained. The three strategies which were selected by the students more than the other strategies were: "connecting the word with its synonyms and antonyms", "using physical action when studying new words" and "studying the word with a pictorial representation of its meaning". Among these three frequently-used strategies, the first one was selected by forty eight percent of the students and so according to the students' responses it is the most frequently-used vocabulary learning strategy. After that twenty three of the students asserted that they use the second strategy that is "using physical actions while studying new words". It means that they do some physical actions (like shaking hand) in order to make a connection between the meaning of that word and the action. In this way, whenever they encounter that word, unintentionally they remember the action and as a result, the meaning of that word. The third frequently-used strategy which the participants of this study selected was "studying the word with a pictorial representation of its meaning". Thirteen of the students selected it. This vocabulary learning strategy is in this way that when a new word is read a picture which is somehow related to its 
meaning is shaped in the learner's mind and in this way that meaning can be easily learned. As to the least frequentlyused vocabulary strategies, "Imaging word form" and "imaging word meaning" methods were chosen to be used in very rare situations. With regard to these findings, it should be pointed out that they were not congruent with the findings of other studies conducted in other contexts like the study done by Atay and Ozbulgan (2007). In their study, "connecting the new word to a previous personal experience" and "use of semantic maps" were the strategies most commonly used by the participants of that study.

To be more detailed on the participants' responses, other than the three frequently used strategies which were mentioned above, some other strategies were also selected by some of the students. Among them, the followings can be mentioned: "grouping the words", "saying the word aloud when studying", "associating the word with its coordinates" and "connecting the word to a previous personal experience". These strategies were selected by some of the responses. The interesting point is that two of the strategies weren't selected by any of the students. These two strategies were: "peg method" and "loci method". After the study, some of the students said that they even hadn't heard those strategies. In the mean time, five of the students wrote down, in the provided space in the questionnaire, that they used other strategies not mentioned in the card. These strategies were: "imaging word's meaning" and "imaging word form". These two ones were again somehow strange to the author. They were in this way that, according to their description, while learning a new vocabulary item, they try to imagine its meaning and also its form to better understanding the meaning of that word.

\section{CONCLUSION}

This study tried to examine first of all, if there is any significant difference between the male and female language learners in terms of their adoption of vocabulary learning strategies. And second, the study made an attempt to ascertain the most and also the least frequently-used of them. To do so, a study was done on two groups of students and they were asked to select three of the strategies that they employ to learn the meaning of new vocabulary items. As it was mentioned in the previous section, "connecting the word with its synonyms and antonyms", "using physical action when studying new words" and "studying the word with a pictorial representation of its meaning" turned out to be used more than other strategies. As to the least frequently-used vocabulary strategies, "Imaging word form" and "imaging word meaning" methods were chosen to be used not so often.

In the end, it should be mentioned that although the number of the participants in this study was not so big to make a definite conclusion, it should be remembered that this study was just a representative of many other studies which have been done regarding the same topic. Therefore, in order to reach a definite conclusion the findings of these studies should be gathered and then by comparing and analyzing them, finding the most and the least frequently-used strategies will be possible.

\section{REFERENCES}

[1] Ahmed, M. O. (1989). Vocabulary learning strategies. Beyond words (pp. 3-14). London: British Association for Applied Linguistics.

[2] Allen, V. F. (1983). Techniques in teaching vocabulary. New York: Oxford University Press.

[3] Anderson, J. R. (1976). Language, memory and thought. Hillsdale, NJ: Erlbaum.

[4] Atay, D. Ozbulgan, C. (2007). Memory strategy instruction, contextual learning and ESP vocabulary recall. English for Specific Purposes 26, 39-51.

[5] Bialystok, E. (1979). The role of conscious strategies in second language proficiency. Canadian Modern Language Review, 35, 372-394.

[6] Cohen, A. D. (1996). Verbal reports as source of insights into second language learner strategies. Applied Language Learning, 7(1), 5-24.

[7] Cohen, A. D., Weaver, S. F., \& Li, T. (1998). The impact of strategic-based instruction on speaking a foreign language. In A. Cohen (Ed.), Strategies in learning and using a second language (pp. 107-156). London: Longman.

[8] Folse, K. S. (2004). Vocabulary myths. Ann Arbor, MI: University of Michigan Press.

[9] Gu, P. Y. (1994). Vocabulary learning strategies of good and poor Chinese EFL learners. In B. Bird, P. Flavey, A.B.M. Tsui, D.M. Allison, \& A. Mc Neill (Eds.). Language and Learning (pp. 376-401). Hong Kong: the Education Department (ERIC Document Reproduction Service No. ED. 370-411).

[10] Gu P. Y. (2005). Learning strategies: Prototypical core and dimensions of variation. Retrieved December 12 , http://www.crie.org.nz/research_paper/peter_Gu.pdf.

[11] Macaro, E. (2005). Fourteen features of a language learner strategy. Retrieved December 12 from http: //www.crie.org.nz/research_paper/1Ernesto_Macaro_WP4.pdf.

[12] McGeoch, J. A. \& McDonald, W. T. (1031). Meaningful relation and retroactive inhibition. American Journal of Psychology 43, 579-588.

[13] Naiman, N., Frohlich, M., \& Todesco, A. (1975). The good second language learner. TESL Talk 6, 58-75.

[14] Nation, P. (2001). Learning vocabulary in another language. Cambridge: Cambridge University Press.

[15] Oxford, R. L. (1990). Language learning strategies: What every teacher should know. Boston: Newbury House.

[16] Oxford, R. L. (1993). Research on second language learning strategies. Annual Review of Applied Linguistics, 13,175-187.

[17] Oxford, R. L. (1996). Employing a questionnaire to assess the use of language learning strategies. Applied Language Learning, $7(1), 25-45$. 
[18] Oxford, R.L., \& Crookall, D. (1989). Research on language learning strategies: Methods, findings, and instructional issues. Modern Language Journal 73, 404-419.

[19] Read, J. (2000). Assessing vocabulary. Oxford: Oxford University Press.

[20] Rubin, J. (1975). What the "good language learner" can teach us. TESOL Quarterly, 9, 41-51.

[21] Richards, J. G., \& Renandya, W. A. (2002). Methodology in language teaching: An anthology of current practice. Cambridge: Cambridge University Press.

[22] Sanaoui, R. (1995). Adult learners' approaches to learning vocabulary in second languages. The Modern Language Journal 79, $15-28$.

[23] Schmitt, N. (1997). Vocabulary learning strategies. In R. Carter \& M. McCarthy (Eds.), Vocabulary and language teaching (pp. 198-218). New York: Longman.

[24] Schmitt, N. (2000). Vocabulary in language teaching. Cambridge: Cambridge University Press.

[25] Waring, R. (1997). The negative effects of learning words in semantic sets: A replication. System 25(2), 261-274.

[26] Wenden, A. (1985). What do second-language learners know about their language learning? A second look at retrospective accounts. Applied Linguistics, 7, 186-205.

[27] Wenden, A. (1991). Learner strategies for learner autonomy. Englewood Cliffs, NJ: Prentice-Hall International.

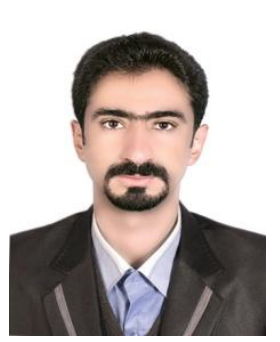

Kamal Heidari Soureshjani was born in Shahrekord on the 29th of July in 1986. He got an M.A degree in TEFL from Shiraz University, Shiraz, Iran in 2010.

He has been teaching TOEFL and IELTS and also a range of English modules in Islamic Azad and Payame noor universities. He also compiled a book wrote a host of papers in related field. His research interest is LA, applied linguistics, and language skill studies.

Mr. Heidari is now an academic member of Young Researchers Club in Iran. 